\title{
PAISAJE CULTURAL EFÍMERO. EL PATRIMONIO VERNÁCULO MAYA EN SU RELACIÓN CON EL TERRITORIO
}

\section{Paisagem cultural efêmera.}

A herança Maia vernacular em sua relação com o territorio.

Ephemeral cultural landscape.

The vernacular Mayan heritage in its relationship with the territory

\section{Aurelio Sánchez Suárez}

Académico e Investigador Coordinador de la Unidad de Ciencias Sociales, Centro de investigación Regional.Universidad Autónoma de Yucatán, Merida, México.

asanchez@correo.uady.mx

https://orcid.org/0000-0002-2429-0052

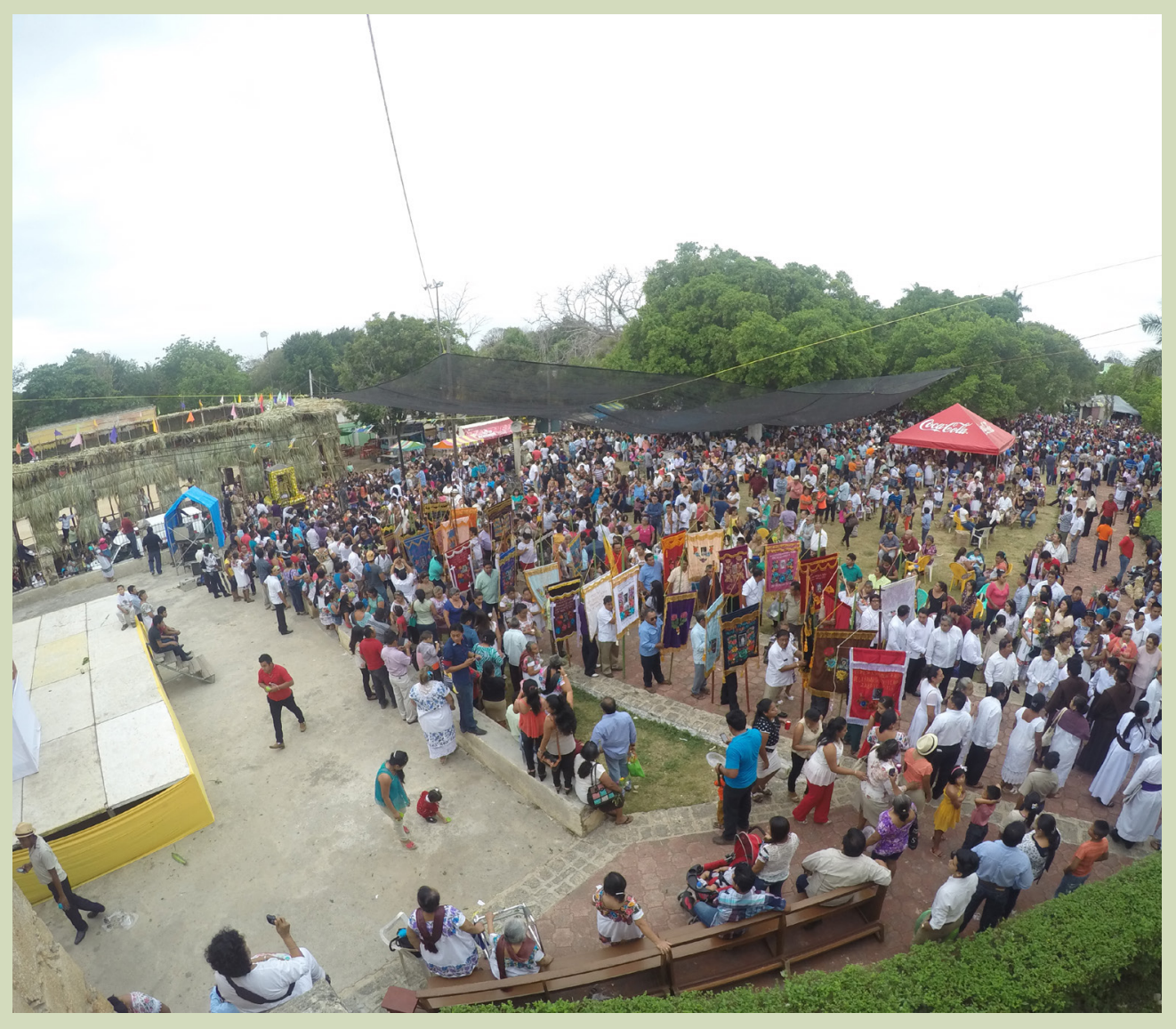

Proyecto:

"Conocimiento constructivo maya. Estudio de los saberes vinculados a la arquitectura vernácula en dos localidades mayas", CB 2013/221071, SEP-CONACyT, Modalidad: Cuerpos Académicos, periodo 2014-2017.

Vista del paisaje cultural efímero con el tablado, el atrio del templo y la procesión de gremios $y$ el santo patrono San Diego de Alcala. Nunkini. Fuente Aurelio Sánchez Suárez, 2017. 


\section{RESUMEN}

Para los mayas la subjetivación de las cosas es esencial en su filosofía de habitar el territorio, en donde todos son sujetos; por lo tanto, su arquitectura vernácula también asume esta percepción al cobrar vida la casa. Para llegar a este precepto, se desarrolló un proyecto de investigación que buscó entender los procesos de transmisión de los saberes para amarrar (construir) su arquitectura vernácula, en un estudio que involucró metodologías tanto del área de la arquitectura como de la antropología. Durante el levantamiento de datos arquitectónicos se percató de este proceso de vida de las casas de los mayas, las cuales, al ser de materiales perecederos en su mayoría, llegan a un tiempo de vida, pero a la par se están amarrando nuevas casas que cobrarán vida cuando sean habitadas por las nuevas familias. Lo anterior hace de la arquitectura vernácula de los mayas efímera. Estos saberes constructivos también se han utilizado para crear otra arquitectura mucho más efímera: los tablados (coso taurino) para las corridas de toros; al estar estos tablados vinculados con la fiesta patronal, su existencia es de sólo una semana, conformando un paisaje cultural efímero propio de las poblaciones mayas de la Península de Yucatán. Esta cualidad de lo efímero hace de la arquitectura vernácula maya una característica esencial, pero también son parte vital de su existir al ser los escenarios de aprendizaje de los saberes constructivos.

Palabras clave: Paisajes, cultura, arquitectura efímera, arquitectura vernácula, tablados.

\section{RESUMO}

Para os maias a subjetivação das coisas é essencial em sua filosofia de habitar o território onde todos estão sujeitos; portanto, sua arquitetura vernacular também assume essa percepção, dando vida à casa. Para atingir esse preceito, foi desenvolvido um projeto de pesquisa que buscava entender os processos de transmissão de conhecimento para amarrar (construir) sua arquitetura vernacular, em um estudo que envolveu metodologias tanto da área de arquitetura quanto da antropologia. Durante a pesquisa de dados arquitetônicos, percebeu-se esse processo de vida das casas maias que, sendo principalmente materiais perecíveis, atingem um tempo de uso mas, ao mesmo tempo, novas casas que ganharão vida ao serem habitadas por novas famílias. O exposto acima torna a arquitetura vernacular dos maias efêmera. Esses conhecimentos construtivos também foram usados para criar outra arquitetura muito mais efêmera: tablados para touradas, ligados aos santos padroeiros, sua existência é de apenas uma semana, formando uma paisagem cultural efêmera, típica das populações maias da península de Yucatán. Essa qualidade do efêmero torna a arquitetura vernacular maia uma característica essencial, mas elas também são uma parte vital de sua existência, pois são os cenários de aprendizagem do conhecimento construtivo.

Palavras-chave: Paisagens, cultura, arquitetura efêmera, arquitetura vernacular, tablados.

\section{ABSTRACT}

For the Mayans, the subjectivation of things is essential in their philosophy of inhabiting the territory, where they are all subjects; therefore, their vernacular architecture also assumes this perception on bringing the house to life. To arrive at this precept, a research project was developed that sought to understand the processes of transferring knowledge to tie (build) their vernacular architecture, in a study that involved methodologies of both the area of architecture and anthropology. While surveying architectural data, this process of life of the Mayan houses was noticed, which, on mainly being made from short-lasting materials, have a given lifespan but, at the same time, new houses are being tied, that will come alive when they are inhabited by new families. This makes the vernacular architecture of the Mayans ephemeral. The knowledge to tie-up has also been used to create another much more ephemeral architecture: The "tablados" (bullrings) for bullfights. On these "tablados" being linked to the patron saint, they only exist for one week, forming an ephemeral cultural landscape typical of the Mayan populations of the Yucatan Peninsula. This ephemeral quality is an essential characteristic of the Mayan vernacular architecture, but they are also a vital part of their existence on being the scenarios to learn about construction.

Keywords: Landscapes, culture, ephemeral architecture, vernacular architecture, tablados. 


\section{INTRODUCCIÓN}

PAISAJE CULTURAL EFÍMERO

EL PATRIMONIO VERNÁCULO MAYA EN SU RELACIÓN CON EL TERRITORIO
Los antecedentes del paisaje cultural se remontan al estudio sobre el territorio; este concepto fue abordado particularmente por geógrafos con la terminología propia de su disciplina, pero analizando los elementos que hoy se definen como parte del paisaje cultural, la relación del hombre con la naturaleza. Asimismo, fue vinculado con el estudio del ecomuseo relacionado con ciertos círculos de museografía en el siglo XX (Aplin, 2007, p. 429), nuevamente vinculando las acciones del hombre en el territorio, en este caso, como medida de preservación del patrimonio cultural, natural y el desarrollo de las comunidades.

Otros estudios vinculan al paisaje con valores relacionados con la naturaleza y sus características geomorfológicas, clima, vegetación, fauna, agua y modificaciones antrópicas (Muñoz-Pedreros, 2004, p. 123); esta relación con el hombre también es vista como indicador de la calidad ambiental, recurso económico y, en un sentido más amplio, como patrimonio cultural e histórico. Al respecto Galindo González y Sabaté Bel (2009, p. 23) describen esta relación de naturaleza y cultura como una "realidad continuamente evolutiva; paisaje y territorio no como mero soporte, sino como factor básico de cualquier transformación," integrándole a la naturaleza el sentido de cultura, identidad y patrimonio.

En esta línea de integración de lo natural con lo cultural, el Convenio Europeo del Paisaje (2000, p. 2) señala que: "por paisaje se entenderá cualquier parte del territorio tal como la percibe la población, cuyo carácter sea el resultado de la acción y la interacción de factores naturales y/o humanos." El término paisaje cultural fue cobrando más fuerza al grado de poder ser incluido como categoría en la Lista del Patrimonio Mundial (WHL por sus siglas en inglés), en los informes de los debates de la sesión del World Heritage Bureau de 1991, que con ligeros cambios en la reunión de expertos sobre el tema de paisaje en Francia de 1992 (Aplin, 2007, p. 430), pudo ser incluido en la WHL.

Lo anterior lleva a establecer una definición general para el paisaje cultural, de la cual pueden derivar definiciones con especificidades de cada región biológica y cultural, partiendo de que los paisajes culturales se entienden como "bienes culturales que representan las 'obras conjuntas del hombre y la naturaleza' designados en el artículo I de la Convención. Son ilustrativos de la evolución de la sociedad humana y los asentamientos en el tiempo, bajo la influencia de las restricciones físicas y/o las oportunidades que presenta el entorno natural y de las fuerzas sociales, económicas y culturales sucesivas, internas y externas" (UNESCO-ICOMOS, 2009, p. 7).

Las distintas definiciones del paisaje cultural nos dan una muestra de la diversidad de paisajes culturales, más no cubren en su totalidad los existentes en el mundo. Un gran avance en el entendimiento del paisaje cultural ha sido la participación de diversas disciplinas en los estudios. Aplin (2007, p. 430) señala al respecto:

Archaeology and history will be particularly important in the case of the category of 'fossil/relict landscapes', while ethnography and 

'associative landscapes', and economics and studies of human activity patterns for 'continuing landscapes.'. [arqueología y la historia serán particularmente importantes en el caso de la categoría de 'paisajes fósiles/relictos', mientras que la etnografía y la antropología serán relativamente más importantes cuando se trata de 'paisajes asociativos'; finalmente, la economía y los estudios de patrones de actividad humana para los 'paisajes continuos'].

La actividad multidisciplinaria en el tema ha llevado a ampliar la definición de paisaje cultural, incluyendo con más énfasis las actividades humanas que vinculan a la protección, no sólo de lo natural, sino de lo cultural en su expresión del patrimonio inmaterial. Con esto se aborda los diversos aspectos de la apreciación del paisaje, considerando, además de lo escénico, las diferentes formas de percepción (auditiva, visual, olfativa) emanadas de la cultura de cada grupo social (Álvarez Muñarriz, 20 I I, p. 59; Convenio Europeo del Paisaje, 2000; Muñoz-Pedreros, 2004, p. 140).

Otra ampliación del concepto al tema del paisaje es, en el mismo tenor de la actividad humana, su vinculación con el patrimonio material en la combinación de trabajos de la naturaleza y la humanidad, desarrollados a través de sistemas culturales, económicos y espirituales (Aplin, 2007, p. 431;Amendoeria, 2004, p. 78). El patrimonio edificado (material) juega un papel muy importante en el paisaje cultural, con una vinculación indisoluble del patrimonio inmaterial, aunque estas dos categorías históricamente han sido estudiadas, catalogadas y protegidas por separado, para lo cual la categoría de paisaje cultural da la oportunidad de vincular al patrimonio cultural en sus dos acepciones (tangible e intangible), con su interacción con el entorno natural. Esta interacción con lo natural es lo que ha ampliado la definición del paisaje cultural, agregando conceptos de su relación "los recursos bióticos y factores abióticos donde se puede identificar un ecosistema particular y el paisaje" (Chandia-Juare, 20।3, p. 5).

Lo antes expuesto, con referencia al concepto del paisaje cultural, apoya la importancia patrimonial del tema que se aborda en el presente trabajo. Hablar de paisaje cultural en Yucatán, México, es hablar de la cultura maya, de los elementos que caracterizan su identidad. Esta identidad no es específicamente de lo que mundialmente se habla de los mayas (su arquitectura del periodo mesoamericano), sino de la arquitectura que hoy está vigente, su arquitectura vernácula. Los estudios que se han realizado en torno a la arquitectura vernácula de México fueron disciplinares, algunos buscando los vestigios arqueológicos, otros describiendo sus materiales, otros más su distribución arquitectónica; entre los más trascendentes se pueden mencionar a tres publicaciones: la de Roberth Wauchope (1938), The modern maya house, con el estudio comparativo de la casa de los mayas, de los materiales y de las técnicas constructivas; el libro coordinado por Valeria Prieto (1978), Vivienda campesina en México, que se enfocó en la técnica constructiva abordando aspectos constructivos; y finalmente en 1987 se publica el 
libro Arquitectura vernácula en México, de Francisco López Morales, en el que el patrimonio vernáculo es abordado, además de sus aspectos constructivos, en su característica intangible. Estos libros son un parteaguas en la producción científica del estudio de la arquitectura vernácula al integrar la interdisciplina, a partir de este momento muchas publicaciones tuvieron como referencia estos libros para describir estudios de casos, en busca de entender mejor este tipo de arquitectura, especialmente en la región maya.

Posteriormente, las publicaciones realizadas por Luis Fernando Guerrero Baca (1994, 2007, por mencionar algunos) han nutrido de conocimiento el campo de los sistemas constructivos de tierra, conocimiento que ha logrado recuperar los saberes en sistemas constructivos con tierra como el adobe, el tapial, el cob y el bajareque. El avance científico, que involucró también la interdisciplina, ha permitido retomar las técnicas de tierra para la restauración de monumentos históricos y viviendas vernáculas de varias regiones del país.

En México el tema del paisaje cultural inminentemente se ha integrado a la arquitectura vernácula describiendo la relación de la vivienda y la vegetación, variando de acuerdo con las regiones culturales y geográficas con las que cuenta el país; asimismo, los estudios realizados sobre el paisaje agavero y la participación de las comunidades han enriquecido la definición sobre el tema (Rodríguez Figueroa y Avendaño Enciso, 2015; Gómez Arriola, 2015).

Para la zona maya de México se han realizado publicaciones en revistas de diferentes disciplinas donde se aborda la casa de los mayas desde distintos enfoques. Los aspectos descritos en las publicaciones van desde la técnica constructiva, tipología de la vivienda, morfología del solar y hábitat vernáculo (Sánchez, 2006, 2014), hasta los aspectos intangibles como los usos y costumbres (Sánchez, 2006, 20l4), pasando por los aspectos conceptuales de la cosmovisión, saberes constructivos y la problemática que enfrenta este patrimonio en la actualidad (Sánchez, 20 I3, 20 I4, 20 I5).

Las publicaciones mencionadas son sólo una parte de la producción académica, existen otras publicaciones y tesis que abordan casos y temas muy específicos, desde distintas disciplinas como la antropología, la arquitectura y la poesía, imposible de abordarlas todas en este trabajo.

Los estudios basados en la transdisciplina han aportado grandes avances en la definición de nuevos conceptos que ayudan a comprender mejor este microcosmos que es la arquitectura vernácula de los mayas. Disciplinas como la historia de las ideas, la biología, la etnología, la arquitectura, la ingeniería, la antropología, la ecología, la arqueología, han logrado reunir diversas visiones para un mismo fin, entender los componentes materiales, inmateriales y naturales que han permitido que la casa de los mayas siga siendo vigente (Sánchez, 2018). La parte más importante ha sido también el avance en el diálogo con los Maestros Constructores que permite entender, desde su visión, la semiótica de la estructura de la casa y su vinculación con los estudios realizados sobre la cosmovisión de los pueblos originarios. 


\section{METODOLOGÍA}

1 Amarrar es el verbo utilizado en maya para referirse a la construcción de la casa, ya que esta es amarrada en la totalidad de su estructura. Este mismo concepto es utilizado para la construcción de los tablados, los ruedos de madera amarrados para la corrida de toros, ya que es el mismo sistema constructivo de la casa repetido para formar palcos.
Esta forma de habitar el territorio de los mayas los ha llevado a diseñar y amarrar ${ }^{1}$ nuevos espacios que amplían el concepto de paisaje cultural maya, para recrear cada año el paisaje cultural efímero, paisaje ligado a las fiestas patronales de poblados mayas de Yucatán, Quintana Roo y Campeche. En un proceso de apropiación, el pueblo maya retoma la tauromaquia para resignificarla a ritos propios de la cultura maya y cristianos; ligando así la corrida a la fiesta patronal para un camino diferente al de las temporadas taurinas, por lo cual, la corrida sólo se celebra una vez al año. La arquitectura vernácula que genera el pueblo maya, basada en sus saberes ancestrales, es efímera pero permanente por su condición de patrimonio inmaterial, configurando los escenarios de aprendizaje que lo ha preservado por siglos. Lo anterior fue parte de los resultados del proyecto de investigación "Conocimiento constructivo maya. Estudio de los saberes vinculados a la arquitectura vernácula en dos localidades mayas", con clave: CB-20 I3/22 107I, financiado con recursos de CONACyT.

Dada la complejidad del fenómeno de estudio, el trabajo de investigación requirió de una mirada multidisciplinar, con el uso de métodos concernientes a la arquitectura y la etnografía (Hueso, Cascant, 2012). En este sentido la metodología cualitativa fue la más adecuada para desarrollar la transdisciplina. Dentro de la metodología cualitativa se empleó el método de teoría fundamentada (Páramo, 2015), que nos permitió un estudio exploratorio desde las dos disciplinas y nos condujo a la definición de conceptos basados en la filosofía de los pueblos originarios y la percepción de su arquitectura vernácula.

Las herramientas metodológicas que se aplicaron en el trabajo de campo se desarrollaron basadas en las dos áreas disciplinares: arquitectura y etnografía, con el objeto de recabar la información en los ámbitos patrimoniales de lo material, inmaterial y natural.

Para la obtención de información en trabajo de campo del patrimonio material se utilizaron los métodos propios de la arquitectura, como el levantamiento morfológico del patrón de asentamiento de las comunidades seleccionadas, así como de las expresiones arquitectónicas efímeras de los espacios abiertos. El levantamiento arquitectónico incluyó tanto los espacios abiertos en los que se desarrollan actividades socioculturales, así como de los edificios vinculados a estas manifestaciones, lo cual se complementó con la información generada de los estudios etnográficos.

Para la obtención de información concerniente al patrimonio inmaterial, vinculado a los conceptos filosóficos, se aplicaron instrumentos metodológicos propios de la etnografía, como lo son las entrevistas semidirigidas. Se identificaron actores que son reconocidos por la comunidad de estudio y con la técnica de bola de nieve se fue encontrando a otros actores para entrevistar, hasta llegar a la saturación de la información. 
Figura 1

Maestros que amarran

casas. Nunkiní,

Campeche.

Fuente. Aurelio

Sánchez Suárez,

2017 .
Se apoyó el trabajo con herramientas como grabadoras de audio y de video, para capturar toda la información. Para la documentación de las actividades socioculturales se realizó observación no participativa, lo cual se hizo con la mayor cautela, en especial en los ritos, para no interferir con lo sagrado.

Toda la información recabada se analizó y clasificó después de ser lograda en campo, manteniendo una visión holística en el trabajo de campo. De los resultados obtenidos se clasificaron en varios conceptos, uno de los cuales se presenta aquí, enfocado a la transmisión de saberes y sus escenarios de aprendizaje como paisaje cultural efímero. Los otros resultados se enfocaron en la descripción de los conceptos mayas para definir la capacidad y voluntad de aprender a amarrar, el estudio histórico sobre las expresiones de arquitectura efímera en la Península de Yucatán y el discurso decolonial sobre la exclusión y discriminación de la vivienda maya y la forma de habitar el territorio, los cuales forman parte del libro Amarrando los saberes y los documentales Ichil xa'anil naj y Yáan in wóol in k'axic.

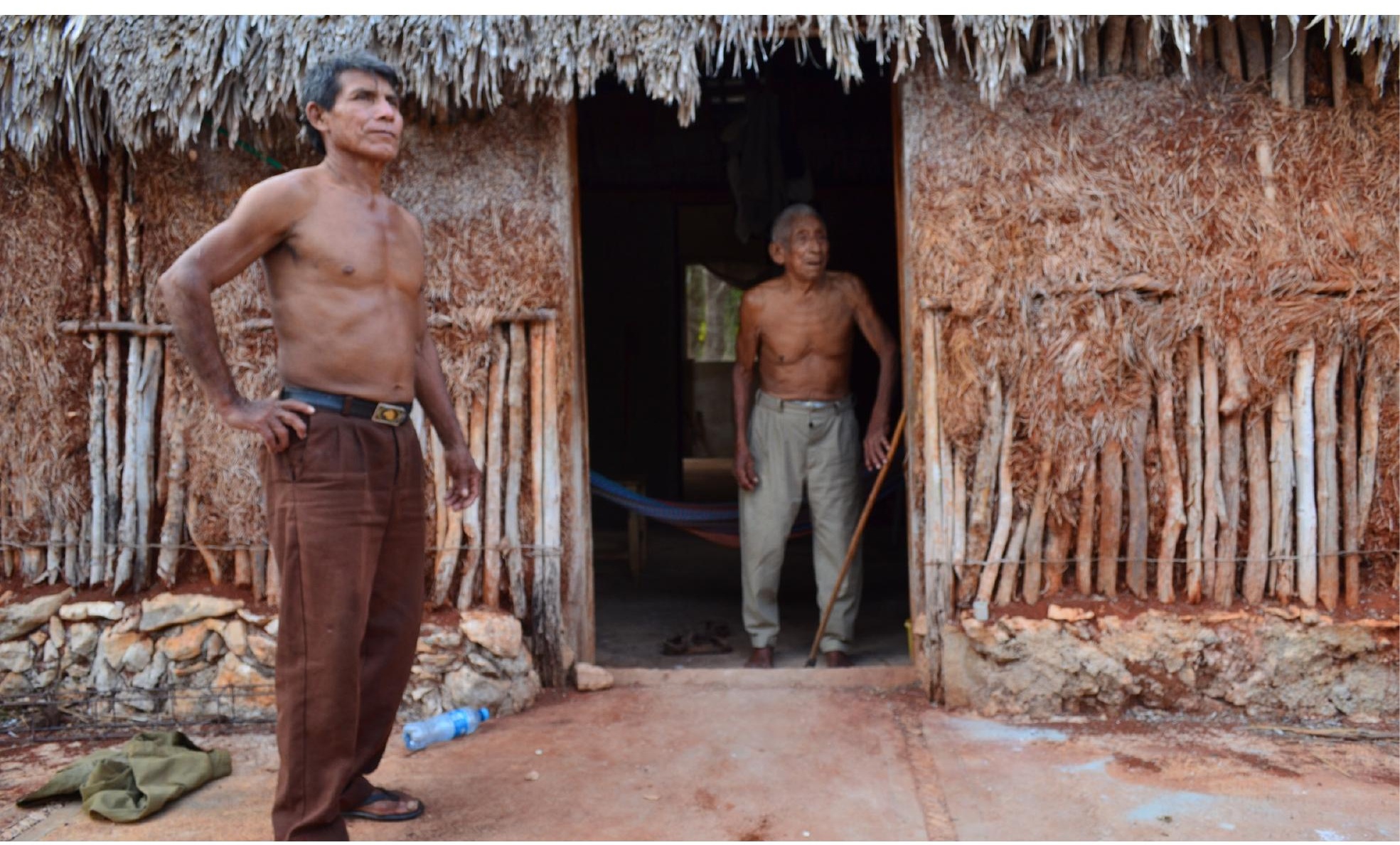




\section{RESULTADOS}

2 La milpa es un sistema agrícola y productivo, articulado a múltiples actividades familiares y comunales. La milpa ha sido el sistema tradicional del uso y manejo de los recursos naturales bajo el sistema de roza-tumba-quema, para sembrar el maíz acompañado del frijol y la calabaza, además de raíces y tubérculos (Terán y Rasmussen, 2009, p. 25, 43).
Un aspecto esencial del estudio es que partimos del concepto de patrimonio inmaterial y su proceso de transmisión, este concepto trascendió a algo más complejo que es el patrimonio biocultural, el cual involucra diversos escenarios de aprendizaje; escenarios en los que se aprenden saberes diversos vinculados con la milpa, así como del patrimonio material del patrón de asentamiento de pueblos mayas.

Este complejo sistema de escenarios de aprendizaje que hemos identificado, no sólo nos amplía la idea del patrimonio inmaterial, sino que nos da elementos para identificar las diferentes causas del deterioro. Son dos escenarios de aprendizaje en los que es necesario tener las condiciones óptimas para la transmisión de los saberes.

El primer escenario es el monte y la práctica de la milpa, ${ }^{2}$ esto implica la existencia de tierras ejidales en las poblaciones y la práctica de la milpa por parte de los habitantes. El hecho es que gran cantidad de ejido se ha perdido en las poblaciones mayas. Lo anterior es sólo un acumulado de la pérdida de la diversidad biológica; diversidad que se requiere que exista en el monte para aprender a identificar las maderas que se utilizan en las viviendas y la construcción del tablado. Asimismo, el cambio en las actividades económicas y la aspiración de los padres por darles mejores oportunidades a sus hijos a través del estudio, han sido también factores que han disminuido el número de personas con el conocimiento biótico, el cual está vinculado con la identificación de las especies madereras. El resultado es que, de ser un saber común, ahora los saberes para amarrar la casa o el tablado es un conocimiento especializado. Si bien, el saber era común, siempre la presencia del arquitecto ha sido necesaria y este caso no es la excepción. Durante el estudio se identificó al Maestro que dirige todo el proceso del amarre de la casa y que domina todas las técnicas para cada elemento y sistema constructivo, así como el conocimiento para identificar los diferentes tipos de madera y las formas de su recolección. El nombre que estos maestros tienen en la comunidad de Nunkiní es "Maestro K'aax naj" [Maestro que amarra casa].

El segundo escenario de aprendizaje es en el solar y en la plaza del pueblo. El solar se convierte en el segundo escenario cuando se decide amarrar una casa, es el momento en el que todos los saberes sobre las maderas del monte empiezan a cobrar sentido y utilidad práctica. Este proceso está ligado a la recolección de los materiales para el amarre de la estructura, el recubrimiento de la cubierta y la construcción de muros de bajareque. En todo el proceso el Maestro k'aax naj dirige la obra. En este trabajo, como en el monte, la participación de los niños es palpable. Las mujeres mayores no participan del todo en el proceso de amarre de la casa, pero eso no impide que desde niñas también se involucren en el proceso de aprendizaje.

La plaza del pueblo, como parte de este segundo escenario de aprendizaje, es un espacio diáfano, vestigio del urbanismo mesoamericano que, por su constante uso en el amarre del tablado para las corri- 


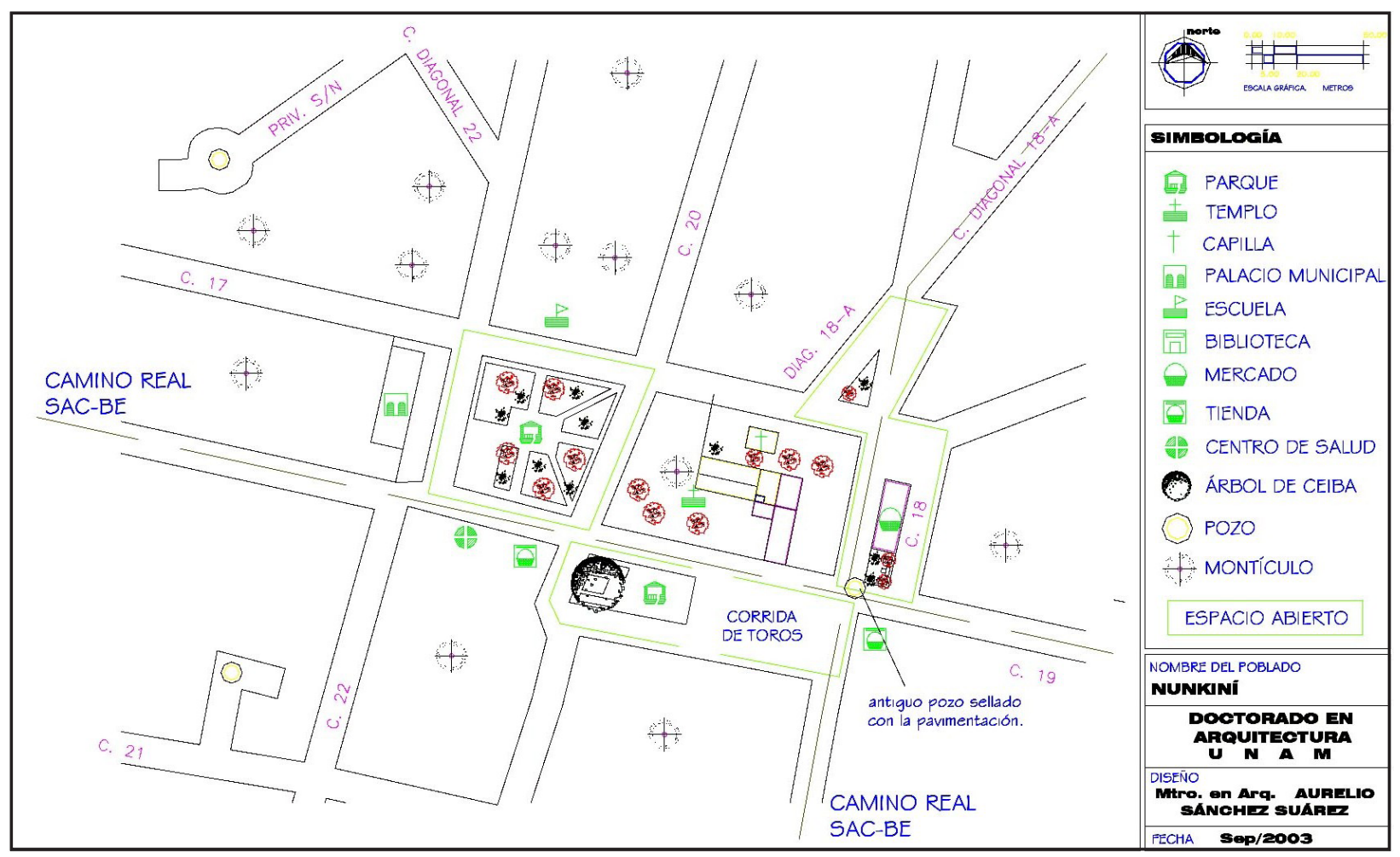

Figura 2

La morfología del

centro la integran

dos espacios abier-

tos en los que se ha

amarrado el tablado.

El espacio generado

por la existencia

del árbol de ceiba

es el actual sitio

del amarre del ta-

blado.

Fuente. Aurelio Sán-

chez Suárez, 2017.

3 Para saber más sobre los tablados como patrimonio cultural consultar "Patrimonio inmaterial y material de la corrida de toros en los pueblos mayas" (Sánchez, 2009). das de toros, permitió que permanecieran sin construcción alguna en la mayoría de los pueblos. ${ }^{3}$ Esta plaza que está íntimamente ligada al templo y en algunos casos al árbol de ceiba, es la que alberga una de las estructuras vernáculas efímeras de gran magnitud; misma que da identidad al paisaje cultural efímero de los pueblos mayas de la península de Yucatán. Los tablados son el escenario vivo de la transmisión de los saberes. Dado que el amarre de las casas es ya muy escaso, por el alto costo que implica construir una casa nueva, fue el amarre anual de los tablados la oportunidad de documentar los procesos claros del aprendizaje. En este punto se identificó que no hay precisamente una enseñanza, sino que es en la práctica cotidiana y anual de estos dos escenarios en los que se adquieren los saberes, los cuales empiezan con el juego y la imitación desde muy temprana edad. La participación de niñas y niños permite que los saberes se adquieran sin distinción de género, permaneciendo los niños cuando van creciendo e involucrándose a trabajos pesados por la carga de la madera. En este instante las niñas se limitan a los roles de la casa, pero los saberes ya los tienen adquiridos.

La cualidad de efímero en los escenarios de aprendizaje es muy clara. En el proceso de la milpa, en el que se tumba el monte para dar paso al policultivo, es dejada descansar después de dos años aproximadamente, permitiendo la regeneración del monte y propiciando un paisaje natural cambiante. Las casas mayas, en su cualidad de ser construidas con mate- 
4 Baile tradicional de jarana con lo que se le da inicio a la fiesta patronal. riales perecederos, pero también en su subjetivación maya, mueren (se abandonan para su destrucción paulatina) cuando sus últimos habitantes dejan de habitarlas, dando paso a otras que ocuparán su lugar o al menos así era hace algunas décadas; dando una temporalidad corta (60 a 100 años) a la arquitectura vernácula maya, en comparación con otras arquitecturas de tierra. Definitivamente el paisaje cultural efímero que está más fortalecido es el de los tablados, tema publicado en la revista Arquitecturas del Sur en su número 47 (Sánchez, 20 I5). Los tablados, al ser una estructura desmontable y de uso exclusivo durante la fiesta, su temporalidad se limita a pocos días, contribuyendo a la conformación de un paisaje efímero, pero recurrente cada año.

Este paisaje se recrea anualmente en una integración de elementos permanentes como lo son el espacio abierto diáfano, el templo cristiano y el árbol de ceiba; en conjunto con los efímeros como son el tablado, los juegos mecánicos, la vaquería ${ }^{4}$ y las procesiones, todo en una festividad que no necesariamente está vinculada al calendario cristiano, sino que, en la mayoría de los casos, está vinculada a la petición de lluvia y buena cosecha, pensamientos que escucharon de sus abuelos, los que ahora organizan las fiestas y es muestra de la vigencia de la relación de los mayas con su entorno natural.
Figura 3

Amarre de una

casa maya con la

presencia de las

tres generaciones.

Nunkiní, Campeche.

Fuente. Aurelio

Sánchez Suárez, 2017.
Figura 4

Amarre del tablado con

la presencia de las tres generaciones. Nunkiní, Campeche.

Fuente. Aurelio Sánchez Suárez, 2017.
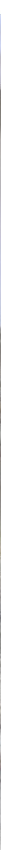


\section{DISCUSIÓN}

De los estudios sobre la cosmovisión se ha podido entender que la construcción de la casa hace referencia a la creación del mundo; un ejemplo es el de la creación de la tierra narrada en el códice del Popol Vuj, muy similar al trazo de la casa maya como inicio de la construcción (Sánchez, García y Eastmond, 2018). También los nombres de elementos estructurales hacen referencia al nivel del cielo con la presencia de los brazos de la tortuga, así como del cuerpo humano, identificado también en narraciones de cuentos mayas. El considerar la casa como un cuerpo, es considerar también su espíritu, transformándola en un ser animado, un sujeto, complementando su característica material para trascender a la subjetivación. Esta característica de espacio vivo es también reconocida por los habitantes, y es por ello que su deterioro es lento, como si fuera una persona que muere; consecuencia de lo anterior, los mayas han sabido conservar su patrimonio vernáculo, siendo la expresión con mayor número de viviendas vernáculas en México.

Al igual que las viviendas mayas, las otras expresiones vernáculas de México tienen una vinculación inherente a los recursos naturales, está vinculación está impregnada de pensamientos que forman la cosmovisión de cada pueblo, su arraigo al territorio. Tierra, madera, fibras naturales, agua, se funden para formar la vivienda que cobrará vida, que se asentará en el territorio como lo ha venido haciendo por milenios. De estos pensamientos nacen conceptos que la diferencian de otras arquitecturas y le asignan un valor inmensurable.

Esta visión holística de la arquitectura vernácula nos ha permitido generar suficiente conocimiento para entender su parte material, por la cual podemos percatarnos de su deterioro y destrucción. Pero la parte inmaterial, que está concentrada en los saberes constructivos, es menos palpable su deterioro. Estos saberes nos han ayudado a ir siguiendo el hilo del patrimonio inmaterial de la arquitectura vernácula, el cual ha conducido a la definición de un patrimonio biocultural.

Durante siglos los recursos naturales fueron explotados, unos con mayor impacto como el periodo del henequén, que fue el comienzo de grandes extensiones de monocultivo; pero la naturaleza es resiliente y se está recuperando en las zonas donde se le ha dejado regenerarse. No así en la deforestación para la cría de ganado, que ha sido también una actividad que ha puesto en riesgo la biodiversidad. Hace algunas décadas otros tipos de monocultivos han estado afectando el monte, mismos que además de deforestar, han estado contaminando el suelo y los mantos freáticos.

Ahora nos enfrentamos a megaproyectos que, en la lógica de generar energía verde, van a deforestar cientos de hectáreas para colocar celdas fotovoltaicas. Pareciera que esto no tiene afectación al patrimonio de los mayas, pero el daño colateral que está provocando la pérdida de la biodiversidad es la eliminación de escenarios de aprendizaje de muchos de los saberes, mismos que vinculan al pueblo con la naturaleza, que proveen de alimento, que permiten agradecer por lo que los señores del monte otorgan, en una filosofía de retribución a la naturaleza 


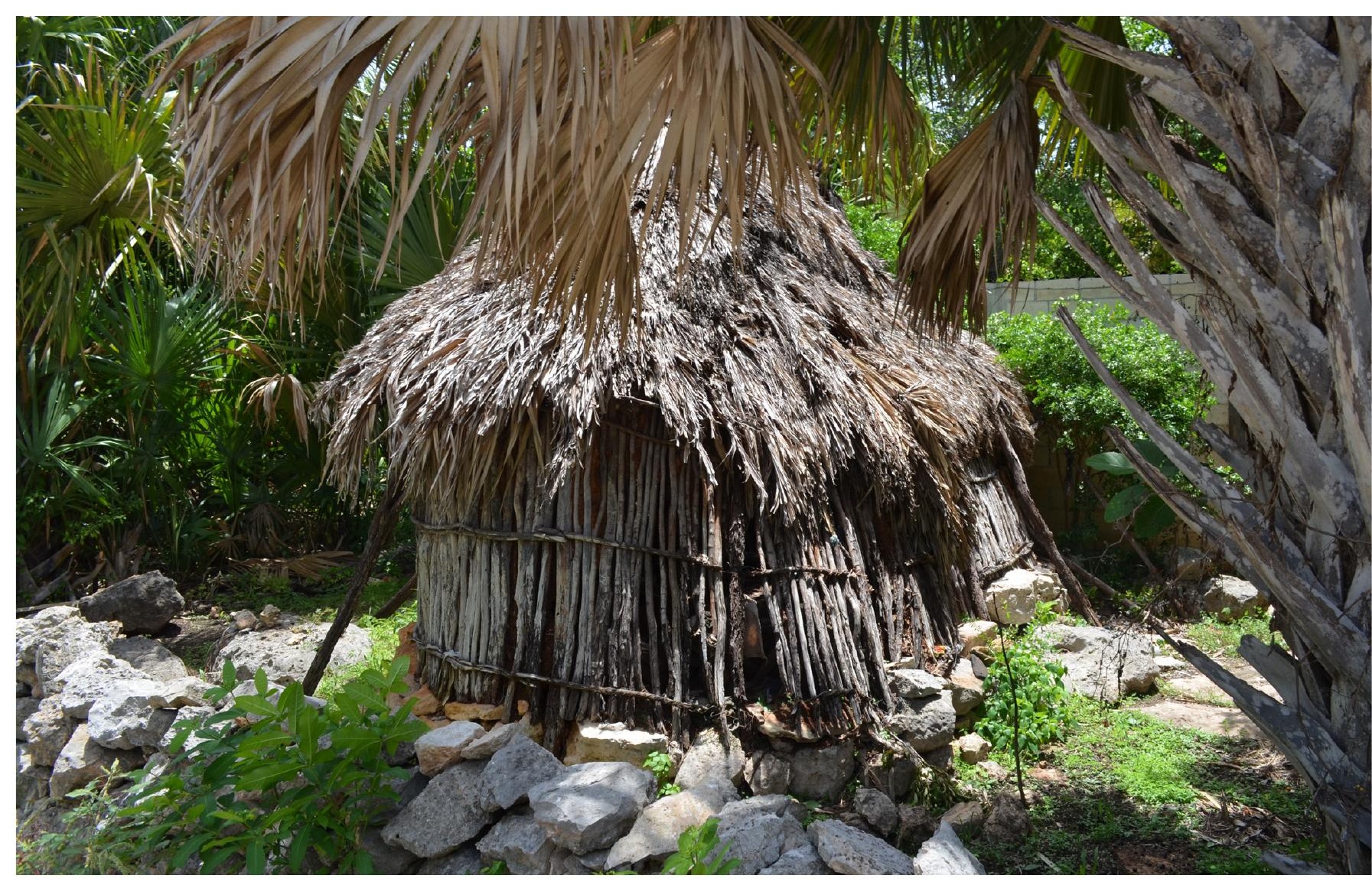

Figura 5

Vivienda que ya no

está habitada, la

familia vive en una

casa adjunta de con-

creto. Nótese los

apoyos de madera

para no caer, po-

dría decirse que la

casa está muriendo.

Nunkiní, Campeche.

Fuente. Aurelio Sán-

chez Suárez, 2015.

y respeto por la vida diversa en el territorio. Lo anterior nos recuerda al recién fallecido Miguel León-Portilla, cuando le preguntaron cómo se definen estas racionalidades y saberes de los pueblos originarios, a lo que él respondió: filosofía.

Esta filosofía para habitar el territorio es la que también recrea el paisaje efímero en los pueblos originarios, en la que los saberes constructivos tienen su escenario de aprendizaje y son actores principales. El tema de la protección de los animales ha impulsado leyes hegemónicas, verticales, que buscan prohibir las corridas sin considerar el proceso de apropiación por parte del pueblo maya; el riesgo de la prohibición es la pérdida del paisaje efímero, afectado también por la remodelación de estos espacios diáfanos para acondicionarlos ante la visita de turistas. Los factores que avezan este paisaje cultural efímero son diversos, por lo cual su preservación es más compleja. 


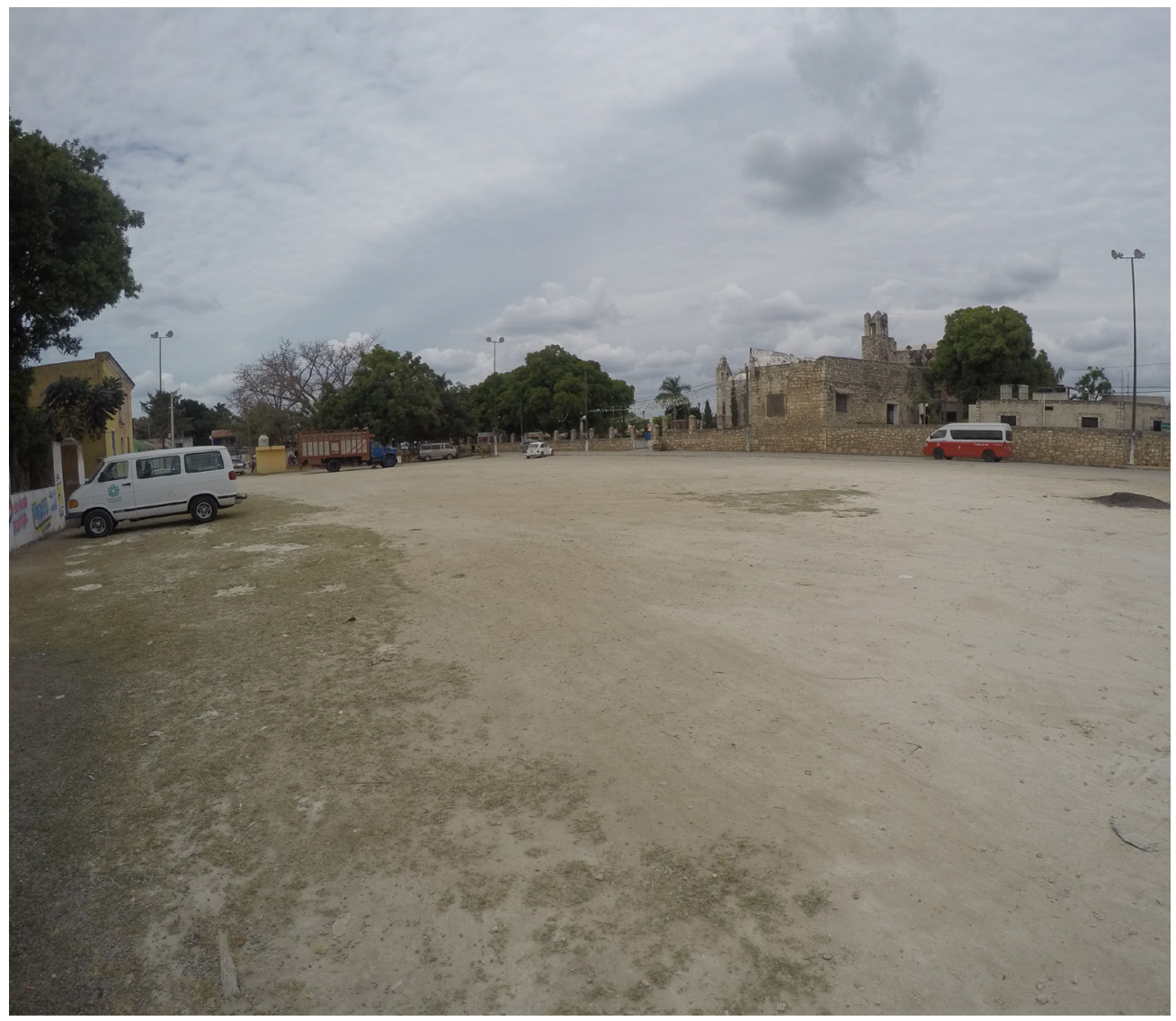

Figura 6

Vista del espacio abierto generado por el árbol de ceiba,

ubicado en el extremo derecho y sin

hojas. Al frente se aprecia el templo.

Nunkiní, Campeche.

Fuente. Aurelio Sán-

chez Suárez, 2017.

Figura 7

Vista desde el

templo del mis-

mo espacio, con el

tablado amarrado en

tres días, listo

para el inicio de

la fiesta que durará

cinco días. Nunkiní,

Campeche.

Fuente. Aurelio Sánchez Suárez, 2017.

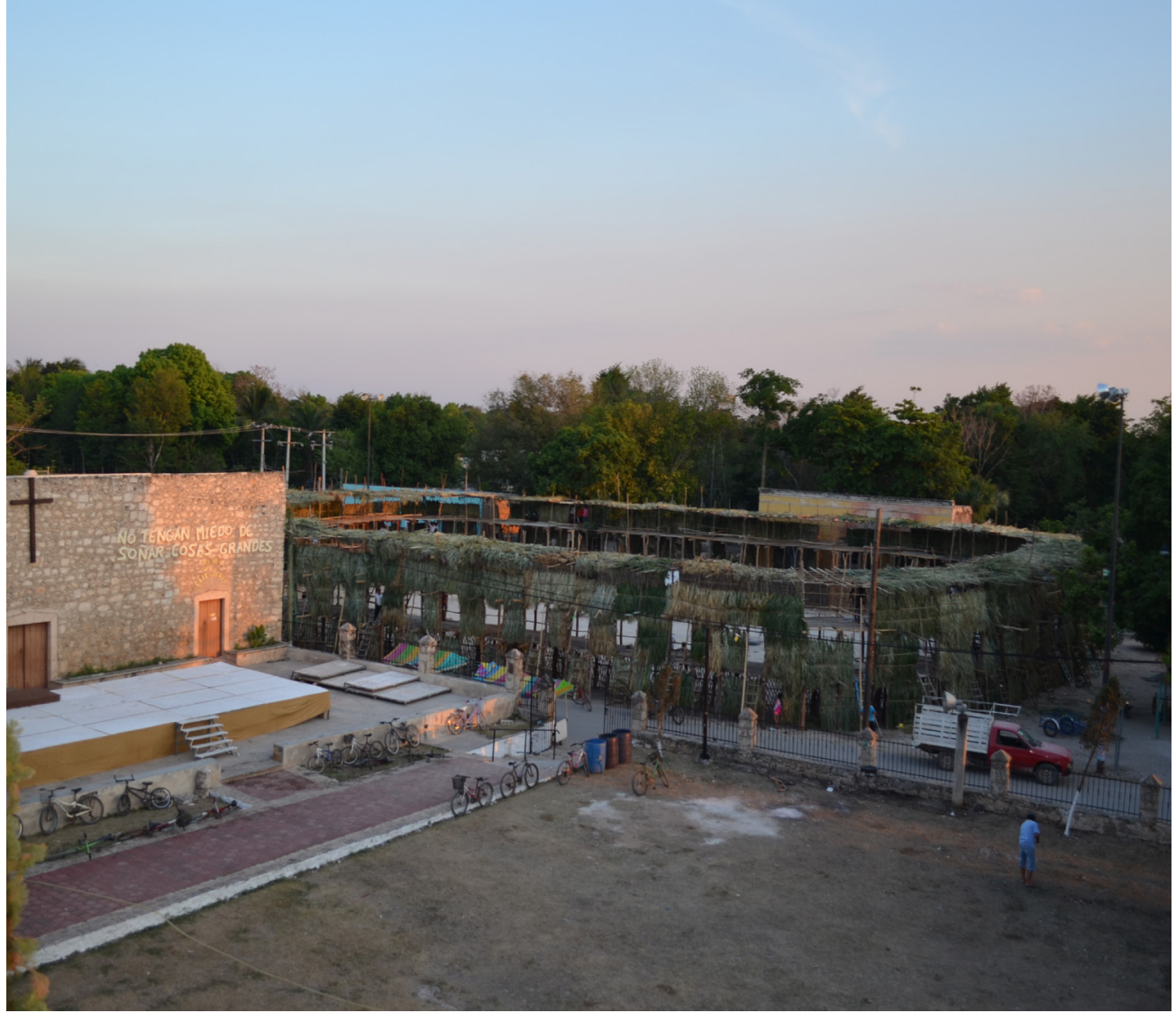




\section{CONCLUSIÓN}

AS / Vol. 38. No57 / ENERO 2020 // ISSN impresa 07 I 6-2677 / ISSN digital 07 I9-6466

PAISAJE CULTURAL EFÍMERO.

EL PATRIMONIO VERNÁCULO MAYA EN SU RELACIÓN CON EL TERRITORIO 


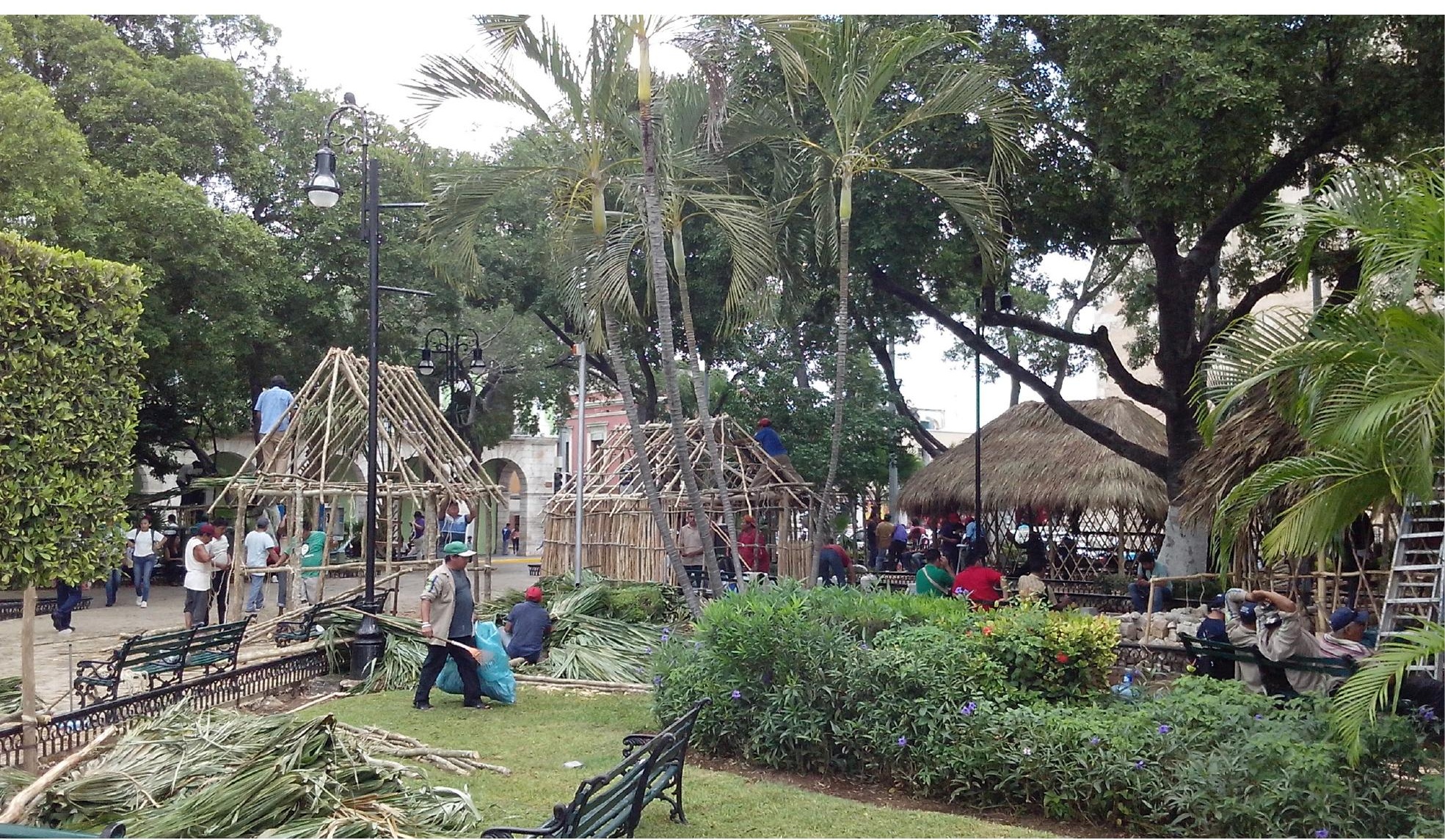

Figura 8

Amarre de estruc-

turas de madera con

diseño de casas para

colocar altares del

día de muertos. Mé-

rida Yucatán.

Fuente. Aurelio Sán-

chez Suárez, 2016.

tradición que es considerada Patrimonio Inmaterial de la Humanidad (desde el 2003); espacios fúnebres se vuelven festivos por efímeros días del mes de noviembre.

En la Península de Yucatán estas festividades comienzan el 31 de octubre con el U hanal palal (comida de difuntos para niños) y continúa el día primero de noviembre. Este paisaje cultural efímero se materializa con los altares que son colocados en los hogares, mismos que perpetúan la tradición y que ahora también se hacen presentes en los cementerios, en las calles y plazas; tal es el caso de la transformación del paisaje urbano de la Plaza Grande de Mérida a un paisaje vernáculo. Pequeñas casas mayas son amarradas, el tsooltuun (enfilar piedras) se hace presente en pequeñas albarradas y pozos simulados junto a las casas; todo este paisaje vernáculo es recreado para albergar los altares del día de muertos. Los saberes constructivos de los mayas nos recuerdan el adecuado uso de materiales traídos del monte para configurar el paisaje cultural efímero y demostrar qué tan permanente está en nuestras tradiciones. 


\section{BIBLIOGRAFÍA}

AS / Vol. 38. No57 / ENERO 2020 // ISSN impresa 07 | 6-2677 / ISSN digital 07 19-6466 